Experiencia de la escuela itinerante de derechos humanos para las mujeres de la Ciudad de México, 2016 a 2018

Delgado, Ochoa Ma. De los Dolores

Hospital Juárez de México, SSA E-mail:

lolgera@hotmail.com

Juárez, Hernández Guadalupe

SEMARNAT

\section{Domínguez ,Marqués Octaviano $\mathbf{H}$}

ESM del IPN

PALAVRAS-CHAVE: Derechos Humanos, equidad de género y comunicación digital

La Constitución Política de México menciona que todas y todos tenemos derechos a educación, trabajo digno, a servicios de salud y más [1], la población femenina es del $51.4 \%$ en la República Mexicana; las mujeres representamos el $52.6 \%(4,687,003)$ del total de población de la Ciudad de México [2], siendo el $62.8 \%$ de mujeres que tienen 15 años y más de lo anterior el $95.8 \%$ son alfabetas y se tiene sin instrucción en primaria un $6.8 \%$, secundaria y medio superior un $18.7 \%$ y de superior y el $16.1 \%$ a nivel superior.[3,4 y 5] Por lo anterior se generó la escuela itinerante de derechos humanos para las mujeres de la Ciudad de México, teniendo como objetivo explicar los derechos humanos y de las mujeres para que tomen conciencia de que existen herramientas jurídicas que las respaldan por ser mujeres. El presente trabajo se realizó en las 16 delegaciones ahora alcaldías, el primer año fueron 8 sedes con 10 talleres de diversos temas como derechos humanos, de la mujer, sobre su cuerpo, derechos económicos, principalmente, el segundo año fueron 10 sedes con 10 talleres se actualizaron las pláticas sobre derechos humanos, de mujeres, se agrego comunicación digital y la relación equidad de género y medio ambiente, para el último año se compactaron a 8 sedes con 8 diferentes talleres teniendo la base los derechos humanos y de la mujer. Se obtuvo que el primer año asistieron aproximadamente 150 participantes capacitándose por mes en cada cede un total de 1,500 mujeres al año, en 2017 fueron 2,000 mujeres capacitas y en el 2018 fueron 2,580 capacitadas, observándose un aumento proporcional del interés de las mujeres por los diferentes talleres, las participantes fueron desde amas de casa, estudiantes y profesionistas, de 15 años y más. Las asistentes aprendieron que tienen derechos y los pueden exigir, conocieron y entendieron la economía de la mujer, así mismo la inequidad entre los hombres y mujeres en diferentes ámbitos de la sociedad. Con el trabajo en la escuela itinerante se concluye que las participante que asistieron invitaron a más mujeres ya que los temas que se impartieron fueron de su interés y los aplicaron en su vida diaria.

\section{REFERÊNCIAS:}

[1] Constitución Política de los Estados Unidos Mexicanos, www.sct.gob.mx/JURE/doc/cpeum.pdf

[2] Instituto Nacional de Estadística y Geografía y Secretaría del Trabajo y Previsión Social (INEGI-STPS). (2016)

[3] Instituto Nacional de Estadística y Geografía (INEGI) (2016).Encuesta Intercensal EIC 2015.Base de datos. México, 2016.

[4] Encuesta Nacional de Ocupación y Empleo. Tercer trimestre 2016. Base de datos. México 2016.Jara, L. (2015, septiembre).

[5] Género y salud en el marco de los ODS. Documento presentado en el XVI EncuentroInternacional de Estadísticas de Género. Desafíos Estadísticos hacia la implementación de la Agenda de Desarrollo Post 2015, Aguascalientes, México. Recuperadoel 13 de enero de 2017.http://www.inegi.org.mx/eventos/2015/genero/doc/ p_s7_LiliaJara.pdf. 